\title{
Significance of Employee Engagement and Individual Well-Being on Organisational Performance in Nigeria
}

\author{
Olatunji David Adekoya ${ }^{1}$, Ibrahim Jimoh ${ }^{2}$, Gideon Okorie ${ }^{3}$, Monisola Olajide ${ }^{4}$ \\ ${ }^{I}$ Faculty of Business and Management, University of Wales Trinity Saint David, United Kingdom \\ ${ }^{2}$ Department of Business and Entrepreneurship, Kwara State University, Nigeria \\ ${ }^{3}$ Department of Economics, University of Nigeria, Nsukka \\ ${ }^{4}$ Department of Accounting, Kwara State University, Nigeria
}

\begin{abstract}
This study measures the significance of employee engagement and individual well-being on organisational performance. The collected data was done through the administration of semi-structured questionnaires and interview. The researchers gathered data from one of Nigeria's top manufacturer of plastics. A total number of 48 questionnaires were administered to the staff of the selected organisation. Correlation analysis was used to test the hypotheses to measure the specified variables. The result shows that employee engagement and individual well-being has a significant effect on efficiency and effectiveness which has strong ability to enhance the organisation performance. It was recommended that the top management of organizations should keep in mind employee engagement various drivers such as empowering the employees, providing full information, support from the top management, aligning efforts with strategy while planning to engage their employees to ensure efficiency and improved performance in their organisation. Secondly, communication within the organisations should focus more on engaging employee, individual well-being, empowering employees, rewards and recognition and building a bond between leaders and employees as strategic objectives. Finally, organisation leaders should adopt a periodic survey with employees to develop a better understanding of the employees' expectation trends over time. Monitoring and tracking employee engagement strategies of an organisation and its competitors can be useful when planning to implement effective employee engagement strategies.
\end{abstract}

Keywords: Employee engagement, individual well-being, competitive advantage, profitability, efficiency, effectiveness.

\subsection{INTRODUCTION}

The survival of organisations in today's highly competitive business environment is dependent on maximising profits from its current capabilities while recognising and adjusting to the fact that organisation and business environment of today is dynamic (McCann, 2015). To enhance or maintain competitive advantage, profitability, efficiency, effectiveness organisation must work hard to create a conducive work environment through employee engagement and their well-being (Sofian, 2016). Employee engagement and well-being have become a crucial concept with the utmost attention to management in today's organisation. In this current and challenging globalised economy, business leaders need a high-performing workforce for growth and survival.

Effective management of employee engagement, employee well-being effectively, and the organisation's objective is crucial to ensuring a sustainable and viable future for their organisation (Hill \&Birkinshaw, 2012).They recognise that a highly engaged workforce can increase innovation, productivity, and bottom-line performance and thus enable employees to be committed to the organisation. More so, empowered employees are said to be in the position to make quick decisions and respond to any changes in the environment. Thus, the process of transferring power, authority with responsibility and accountability to the employees enables organisations to be more flexible and responsive to lead improvements in both individual and organisational performance. This paper explores the concept of employee empowerment and engagement and its relationship to organisational commitment. Thus, this study investigates understanding the link between employee engagement and employee empowerment on organisational commitment. 
Therefore, it is essential for organisations to create a conducive environment that enhances employee engagement and well-being to flourish and tap into their knowledge and human capital. According to Jumah (2016) employees come to work ready to be engaged and emphasised that organisations need to create favourable working conditions for engagement. As engaged employees connect, the multiplier effects of synergy lead to collective actions, which influences organisational performance.

\subsection{Research Question}

The study seeks to provide an answer to the general question, "what is the significance of employee engagement and individual well-being on organizational performance? However, the study intends to provide answers to the following set of sub-questions for clarity and direction.

1. To what extent does employee engagement affect employee effectiveness?

2. What is the impact of employee engagement on organisational performance?

3. To what extent does employee well-being affect an organisation's efficiency?

\subsection{Research Aim and Objectives}

The primary objective of this research is to measure the significance of employee engagement and individual well-being on organisation performance. The study is set out to achieve the following specific objectives:

1. To assess the impact of employee engagement on employee effectiveness.

2. To examine the extent to which employee engagement enhances organisational performance.

3. To determine the extent to which employee well-being affects the organisation's efficiency.

\subsection{LITERATURE REVIEW}

\subsection{Employee Engagement and Individual Well-Being}

Sandhya (2016) suggests that as the concept of employee engagement has not gathered a lot offame and is yet to be appropriately discovered; thus, many definitions have been construed to the understand concept of employee engagement, this is to say that there is no one universally accepted definition on which the ground rules could be set. The organisations are trying their best to incorporate employee engagement according to the way they think is fit or workable as, unlike concepts which are academically proven (TQM, Lean Management, and Business Process Reengineering). The author has also tried to explain the difference between various concepts which has a similar construct as employee engagement. The constructs like commitment, organization citizenship behaviour is based on the same lines as employee engagement, but employee engagement is much more colossal than these concepts, that is, these concepts come under the scope of employee engagement.

Employee engagement as discovered by the author is much more interactive and a two-way exchange process of efforts between an employer and the employee. Most studies manifest that the feeling of being valued by management, a management's interest in employee's well- being or giving more opportunity for employee's growth. According to Taris\& Schaufeli (2015), the well-being of employees at work is dependent upon diverse factors some of which includes; job satisfaction, employee participation, engagement, work-life balance, work environment/conditions, employer-employee relationship status and a few more. It was alluded that these factors can either contribute to an increase or decrease in the productivity of employees and as such, organizations particularly the HR department needs to be sensitive to employees' needs even when they keep it private. It was further implied that cases of depression which may not be work-related can cause a serious problem for organizations and this necessitates for employers to seek the opinions of the affected employee and make critical decisions that will only benefit the employee but also the organization (Soane, 2017). 


\subsection{Employee Engagement}

Sandhya (2016) described engagement as a positive, fulfilling, work-related state of mind characterised by vigour, dedication, and absorption; but it is distinct and is expected to predict a full range of outcomes. Satisfaction among employees is desirable, but satisfied employees may not necessarily display vigour in their work. Employees committed to their organisations may not always have an in-depth commitment to their job. Satisfaction and loyalty are related to performance, but engagement appears overall to be a better predictor of employee performance. Over the years, the definition of employee engagement has evolved and is defined as it relates to the context in which it is used; hence, it is yet to be accrued any universal definition (Rafferty et al., 2015; Ellis \& Sorensen, 2017). According to Ellis \& Sorenson (2015), employee engagement is described within the context of a relationship between an employee and his employer; it relates to the ability of and opportunity given to an employee to willingly participate in the decision-making process and activities whilealso taking affirmative steps to further the organisation's prestige and interests. Engagement of employees with the organisation is how employees feel about their senior executives, the trust that the employees have in the values policies, fairness and the confidence in organisational leadership. The concept of employee engagement originates from two concepts organisation citizenship behaviour (OCB) and employee Commitment (Rafferty et al., 2015).

\subsection{Factors Influencing Employee Engagement}

Many researchers have diagnosed the field of employee engagement to determine the factors that will increase employee engagement in the organisation. The employees are willing and enthusiastic to work where they find meaning. The workplace is the prime spot where employer and employee can come closer together for the benefit of both, the employee feels a sense of community, comfortable space for themselves and find opportunities to contribute to the growth of the organization. Armstrong, Shakespeare-Finch \& Shochet (2016) proposed a new model of engagement like the Maslow's need hierarchy has also been developed by the researchers where the lowest level is the basic need like pay and benefits; higher needs follow once the employee is satisfied to spot opportunities, the possibility of promotion and leadership and the final level of this hierarchy is aligning personal values with the values of the firm and discovering a common objective and a sense of connection. There must be more opportunities to grow and a robust employee-employer relationship for initiating employee engagement (Armstrong, et al, 2016). According to Sofian (2016) there must be five essential factors to create a highly engaged workforce as described in the diagram below.

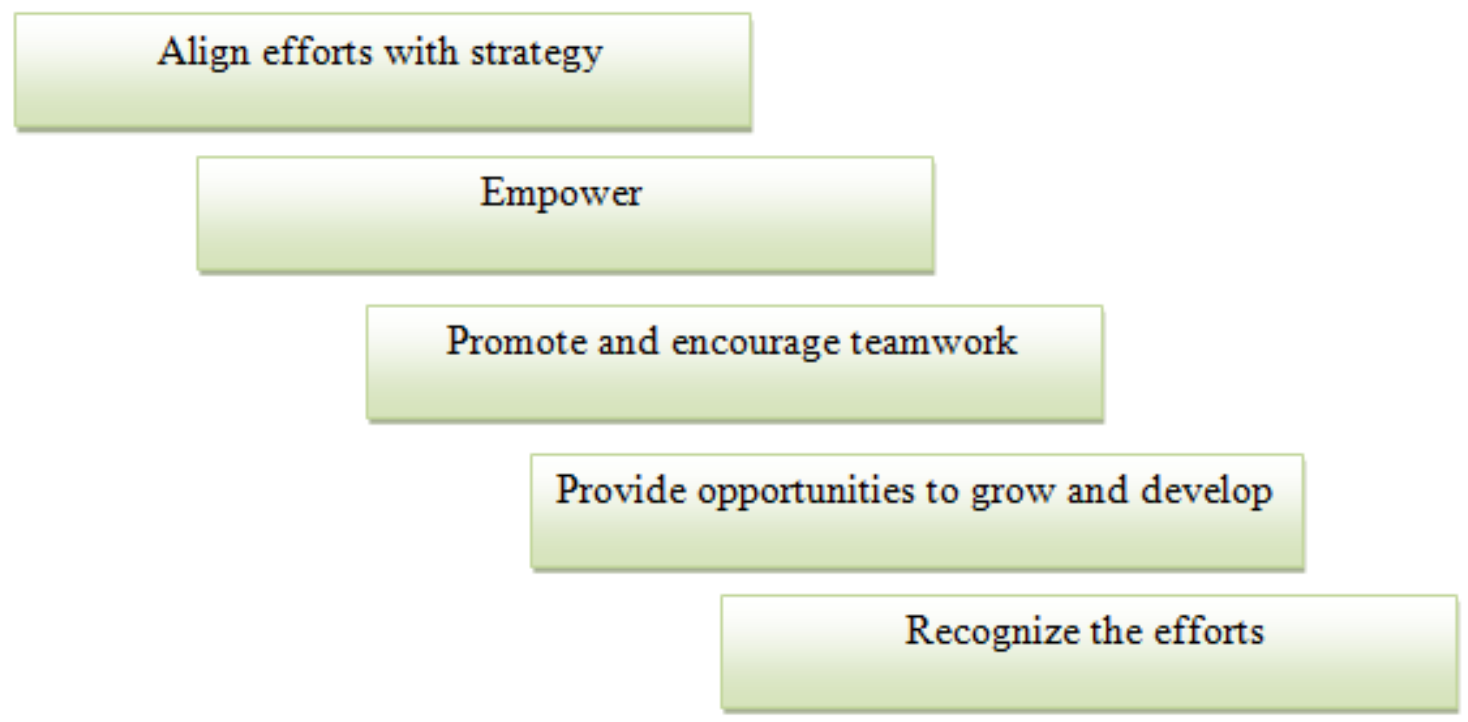

\subsection{Employee Engagement and Organization Performance}

Organisations today are inclining towards employee engagement which is beginning to gain popularity worldwide; the constantly arising dilemma is construed around investing the benefits of employee engagement which is surrounded by elements of employee satisfaction, motivation, and other productivity and financial goals. Studies like (Armstrong et al. 2016; Sofian, 2016; Ellis \& Sorensen, 2017) show a significant relationship 
between employee engagement and well-being and organizational performance. The themes that have been highlighted include but not limited to; customer loyalty, productivity, employee retention, safety, profitability, customer satisfaction, employee satisfaction, retention and absenteeism.

\subsection{The Concept of Performance}

Anitha (2014) asserts that there is no generally acceptable definition of performance and as such, the term performance has been defined differently by various scholars. In traditional terms, performance has been used to describe concepts such as efficiency, effectiveness, improvement, growth and success; these terms have been used interchangeably by researchers such as (Akbaba 2012; Reigonen\&Akinyemi2013). In the same vain Brett (2007) noted that the definitions of successful performance and the variables used to measure performance vary widely.

Organisational performance can be defined as the extent to which an organisation has met its objectives (Sandhya, 2016). It was further stated that companies can determine their performance by assessing their financial and non-financial indicators or Key Performance Indexes (KPIs) against the set goals (Sandhya, 2016). Different organisations have different elements against which their measure performance based on the organisation's objectives. While some companies measure their performance on customer satisfaction, others measure based on the profitability and other in non-profit organizations, the measurement is made against the impact made through their work (Sofian, 2016).

\subsection{Theoretical Review}

This section gives an overview on Resource-Bases View (RBV) and Built-to-ChangeTheory (BCT) as relevant theories to the study.

\subsubsection{Resource-Based View (RBV)}

With traditional strategies focusing on performance enhancement concerning the internal and external environment, the resource-based view is concerned with the pool of resources and capabilities as the primary determinantsof strategy and performance (Armstrong, et al, 2016).Barney (1991 cited in Alonso \&Kok, 2018) advocates that the role of resources in producing firm-wide results should be taken into consideration. Armstrong et al. (2016) ascertains that the difficult it becomes to imitate a product, the more sustainable the competitive advantage given the resources employed. Barney includes human capital in his definition of resources, but it must be unique and imitable. It was further stated that managerial resources are not necessarily scarce unless there is a specific attribute that is not found in any other firm; as such, the resource-based view emphasizes that the uniqueness of each company as critical factor for profitability and that exploiting these differences will maintain and sustain competitiveness. Also, the competency model has become a preferred model for identifying a set of skills, knowledge and values that will align human resources with the organization's strategy (Hamel \& Prahalad, 1994; Armstrong, et al, 2016). It has, therefore, become an essential factor for achieving an organization's overall strategy geared towards fulfilling its set objectives. It can be concluded that the RBV suggests that human resource systems can contribute to organizational performance.

\subsubsection{Built-to-Change Theory (BCT)}

Similar to the RBV, human capital is critical for a competitive advantage in the BCT for organizations; there is a recognition that market value rests with human capital. Research by Bakar \&McCann (2015) has shown that the impact of a firm's human capital management practices, such as training programs, efforts to create an excellent place to work and reward systems do produce superior results. Other research suggests that one of the critical factors is the management of talent (Lawler\& Worley, 2006). Competitive advantage has been evidenced to also rely significantly on the human resource of an organization rather than competing from tangible resources. The BCT developed by Bakar \&McCann (2015) is a continuous change and adaptive method that consists of environmental scenarios and three primary organisational processes - strategising, creating value and designing - which all revolve around the organisation's identity. Organisational capabilities must be created so that change is the key to success. This can be accomplished through a partnership of HR/OD with the organisation building the appropriate structure and configuring the proper talent management initiatives and rewards (Abel, 2013). Talent management includes developing individuals to provide skills as the organisation and jobs change. It may mean hiring individuals who already have the desired skill set but who also are willing 
to change along with the business. This theory, therefore, is essential to understand that organizations need to keep the right people and utilize them using appropriate rewards to spur satisfaction and increased productivity.

In summary, human resource management is concerned with the effective and maximum utilisation of paid labour units an hour; therefore, employee engagement and well-being are one of the single, most important factors to efficiency and effectiveness within an organisation. This concept, which has received extensive coverage and attention has been regarded as a critical driver to competitive advantage and organisational performance. Its impact has come out of the observation that more than ever, employee contribution and behaviour within organisations are a result of their values and perceptions than just management prescriptions. Employee engagement has mostly been used to describe the alignment of an organisation's mission and objective with those of employees. Employee engagement impacts positively on employee behaviours, leading to organisational success, as measured against indicators such as productivity, profitability, safety, customer satisfaction and corporate reputation, employee commitment, essential staff retention among others particularly in changing labour markets.

\subsection{RESEARCH METHODOLOGY}

\subsection{Research Design}

Developing a background knowledge which supports a research process is always rooted in a philosophy which categorised in accordance with its purpose and thinking (Saunders et al., 2011). The approach to the philosophy of this research is epistemology as it constitutes an acceptable knowledge in the area of study. This study was ingrained through the interpretive paradigm but controlled by positivism because it focuses on the understanding of employer and employees' perspective on the significance of employee engagement and individual well-being on organisation performance. This is in line with Choy, (2014) who argued that a combination of positivism and interpretivism are generally used in the management of business research. Positivist research minimises individual judgment and rather stresses the use of established procedures which yields more precise and generalisable results (Choy, 2014). Positivist research is deductive in nature; hence, researchers deal directly with operationalisation, manipulation of empirical variables, prediction and testing (Karkoulian, 2016). Emphasis is placed on methodology, procedure, and statistical measures of validity - which also holds for qualitative research (Levitt, Motulsky, Wertz, Morrow, \&Ponterotto, 2017).

This research uses a deductive approach to achieve accurate analysis to bring about a better understanding of the research topic. The deductive approach is a research strategy to test a hypothesis or theory; that is, moving from theory to research. The array of literature on the theory of employee engagement and individual well-being enable the researchers to confidently employ deductive approach investigate the significance of employee engagement and individual well-being on organisation performance.For this particular study, a survey is considered to be the most suitable method for gathering information and data required to ascertain measure the significance of employee engagement and individual well-being on organisation performance. Consequently, the adoption of survey strategy supports previous studies in a similar area of research (Levitt et al., 2017).

\subsection{Data Source, Collection and Analysis}

Choy (2014) argued that the weakness of both quantitative and qualitative methods could be overcome by employing both methods to provide a more comprehensive, robust and generalised result for the research topic. Based on this, a mixed data collection method was adopted for this research. This study employed the use of quantitative and qualitative data using questionnaire and interview which was obtained for the study. The data for the qualitative study was gathered during a semi-structured interview with top managers who are responsible for, or intimately involved in the policy formulation and implementation employee engagement and individual well-being. Qualitative research such as data collection method via interviews searches for meanings and views held by people. The quantitative data, on the other hand, was also analysed through the administration of a semistructured questionnaire; the mixed method was also adopted by Ellis \&Orensen(2017)in a similar study.

Effective research outcome depends on the quality of data collected. Data were collected from primary sources with the use of a semi-structured questionnaire and semi-structured interview in this study. The researchers gathered data from one of Nigeria's top manufacturers of plastics. One of the human resource executives was interviewed, and 48 set of questionnaires was administered to the staff of the selected 
organisation using a random sampling technique. The retrieved data from the interview and questionnaires were displayed in the data analysis section of this study. The researchers in adherence to the data protection policy has kept the information of the participants confidential, likewise the name of the company where the data was gathered.

Collected data from the respondent was analysed using the Statistical Package for Social Sciences (SPSS). Therefore, a regression analysis was conducted to determine the influence of one variable over the other variables.

\subsection{Ethical Considerations}

The researchers holdan ethical responsibility to inform participants of the purpose, context and broad direction of the study in which they are going to be involved. While carrying out the research, the respondents will not be put under pressure nor intrude their privacy in any way. The information gathered was treated with extreme caution and the identity of respondents remains confidential. The consent of the organisation was sought and obtained before commencement of the research. Also, this research is objective and was not biased in analysing and presenting the results obtained. This research also avoided any form of inappropriate use of information such that will affect the safety of the respondents. The research methodology adopted was appropriate, objectively and carefully selected to present a valid research outcome.

\subsection{DATA ANALYSIS}

\subsection{Statistical Analysis}

The statistical analysis comprised the use of bar charts and pie charts to describe the general views of the respondents while a correlation analysis was conducted to examine the relationship between the variables.
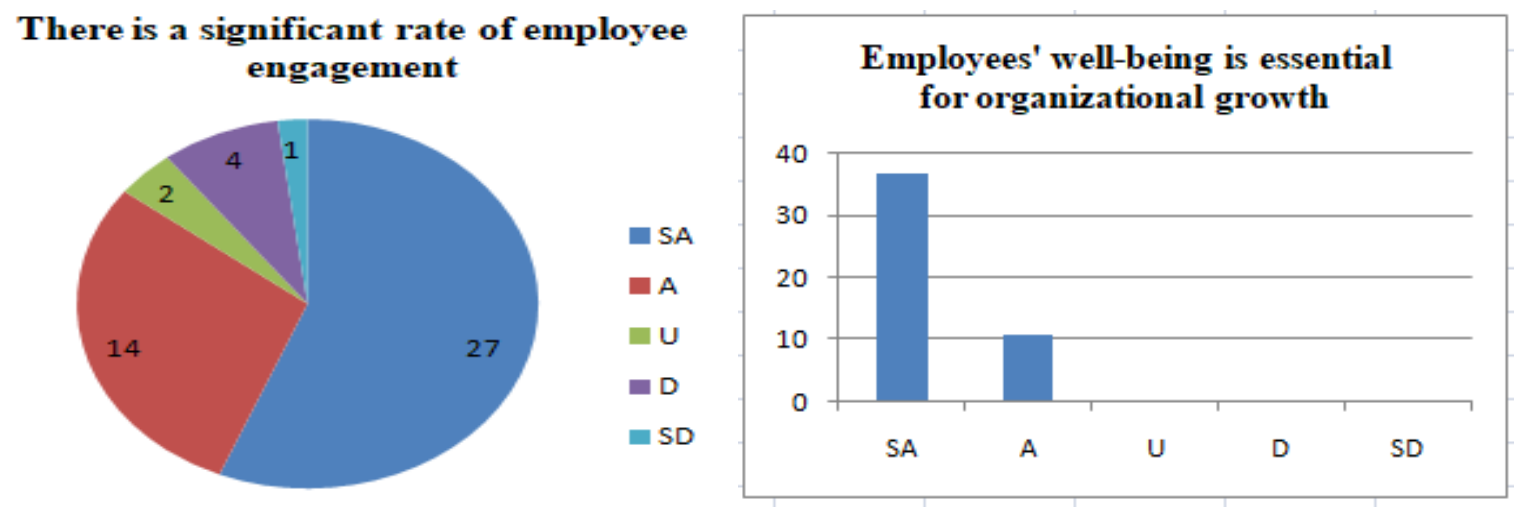

Fig 1: The rate of employee engagement and significance of employee well-being on organizational growth.

The charts above reveal that a significant number of the respondents agree that employee engagement is high in the organization. They also allude that employees' well-being is essential to the growth of the organization. 


\section{Employee engagement prompts organizational efficiency}

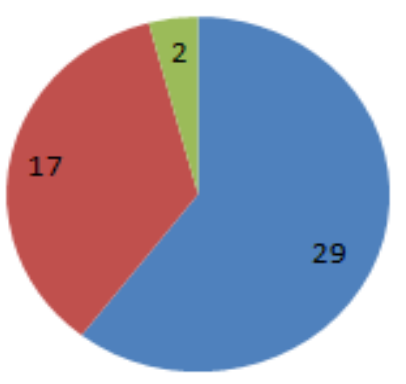

\section{Employee engagement prompts employee and organizational effectiveness}
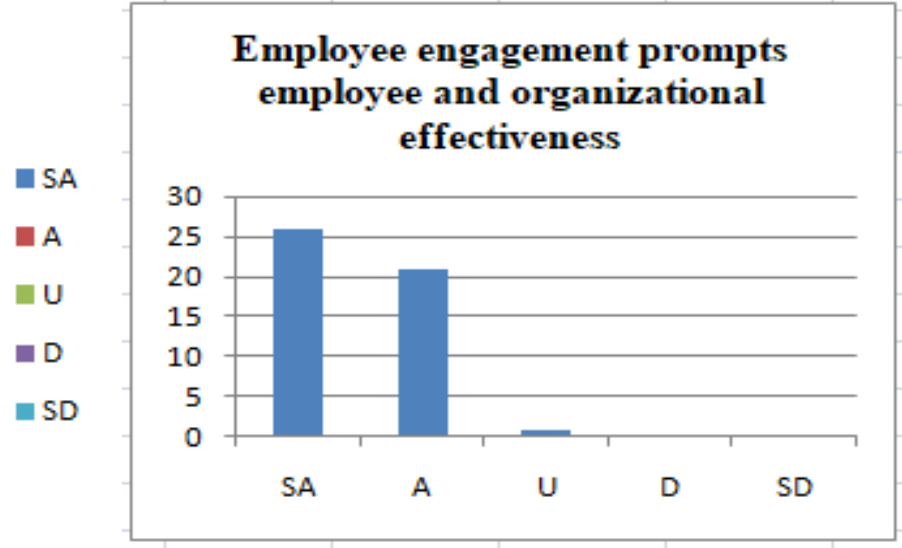

Fig 2: The rate of employee engagement and significance of employee well-being on organizational growth.

The charts in figure 2 reveal that a significant number of the respondents agree that employee engagement have a positive effect on the employee and organization's efficiency and effectiveness.

Table 1: Correlation Coefficient for employee engagement and Organizational efficiency

\begin{tabular}{|ll|r|r|}
\hline & & Employee Engagement & Efficiency \\
\hline \multirow{2}{*}{ Employee engagement } & Pearson Correlation & 1 & $.702^{* *}$ \\
& Sig. (2-tailed) & & .000 \\
& $\mathrm{~N}$ & 48 & 48 \\
& Pearson Correlation & $.702^{* *}$ & 1 \\
Efficiency & Sig. (2-tailed) & .000 & 48 \\
& $\mathrm{~N}$ & 48 & 4 \\
\hline
\end{tabular}

**. Correlation is significant at the 0.001 level (2-tailed).

The above correlation table shows that at a 0.01 level of significance, $r=0.0001$ (2-tailed test). This means that since $r$ is less than 0.01 , there is a positive relationship between employee engagement and the organisation's Efficiency. The significance level of 0.01 implies statistical confidence of above 99\%. By implication, employee engagement and efficiency are significantly correlated. Thus, we reject the null hypothesis $\left(\mathrm{H}_{\mathrm{o}}\right)$ and embrace the alternative hypothesis. $\left(\mathrm{H}_{1}\right)$.

Table 2: Coefficients ${ }^{\mathrm{a}}$

\begin{tabular}{|c|c|c|c|c|c|}
\hline \multirow{2}{*}{ Model } & \multicolumn{2}{|c|}{ Unstandardized Coefficients } & \multirow{2}{*}{$\begin{array}{c}\text { Standardized } \\
\text { Coefficients }\end{array}$} & T & Sig. \\
\cline { 2 - 5 } & $\mathrm{B}$ & Std. Error & Beta & & .002 \\
\hline \multirow{2}{*}{1} & 1.079 & .343 & & 3.150 & .000 \\
\hline
\end{tabular}

a. Dependent Variable: Effectiveness

The coefficient table above shows a simple model that expresses how employee engagement impacted effectiveness. The model is mathematically shown as $\mathrm{Y}=\mathrm{A}+\mathrm{Bx}+\mu$, where $\mathrm{Y}$ is the effectiveness; $\mathrm{A}$ is the constant; $\mathrm{B}$ is the value of coefficient; $\mu$ is the error term. Therefore $\mathrm{EE}=1.079+.723(\mathrm{E})+.078$. This means that for every $100 \%$ increase in effectiveness at the organisation, employee engagement contributed 72.3\%.Thesignificance level below 0.01 indicates statistical confidence of above 99\%. This means that employee engagement affects effectiveness by more than $30 \%$. Thus, the null hypothesis is rejected, and the alternative hypothesis is accepted. 
Table 3: Coefficients ${ }^{a}$

\begin{tabular}{|c|c|c|c|c|c|c|}
\hline \multirow{2}{*}{\multicolumn{2}{|c|}{ Model }} & \multicolumn{2}{|c|}{$\begin{array}{c}\text { Unstandardized } \\
\text { Coefficients }\end{array}$} & \multirow{2}{*}{\begin{tabular}{|c|}
$\begin{array}{c}\text { Standardize } \\
\mathrm{d} \\
\text { Coefficients }\end{array}$ \\
Beta
\end{tabular}} & \multirow[t]{2}{*}{$\mathrm{t}$} & \multirow[t]{2}{*}{ Sig. } \\
\hline & & B & Std. Error & & & \\
\hline \multirow[b]{2}{*}{1} & (Constant) & .748 & .201 & & 3.726 & .000 \\
\hline & $\begin{array}{l}\text { Employee } \\
\text { well-being }\end{array}$ & .846 & .050 & .822 & 16.800 & .000 \\
\hline
\end{tabular}

a. Dependent Variable: Efficiency

The coefficient table above is a simple model that expresses the extent to which employee well-being affects the efficiency of the organisation. The mathematical model is demonstrated below. $\mathrm{Y}=\mathrm{A}+\mathrm{B} \mathrm{x}+\mu$, where $\mathrm{Y}$ is the efficiency; $\mathrm{A}$ is the constant; $\mathrm{B}$ is the value of coefficient; $\mu$ is the error term. Therefore $\mathrm{E}=.748+$ $.846(\mathrm{EW})+.050$. This means that for every $100 \%$ increase in the organisation's efficiency, employee wellbeing contributes $84.6 \%$. The level of significance below 0.01 indicates a statistical confidence level of above $99 \%$. This means that a greater proportion of efficiency increase is as a result of employee well-being.

\title{
4.2 Interview Session
}

Opinions on the effects of employees' engagement on the efficiency and performance of the organisation

One of the HR executives of the organisation was asked to relay his views on the effects of engaging employees on the efficiency and performance of the organisation. The response given revealed that engaging employee is crucial to the organisation's performance. However, the performance of these employees varies based on their educational level.

The engaged employees in possession of a college degree have a level of performance that is greater than those seen among employees in possession of a high school diploma or even less than that. Employee engagement does not only increase focus and efficiency, but it also decreases absenteeism rates. Employees that are engaged recognise the importance of their effort in contributing and care about what they do, towards the success of their employer and the performance of the organisation. It is very important to note that the greater the involvement of employees an organization, the higher the chances of that organization succeeding; this is because employees are tangible assets to the organization and the more they are allowed to have a say in the decisions taken by the organization, the more they are willing to be committed.

\section{Opinions on the impact of employee engagement on the effectiveness of employees in the organisation}

The HR executive was asked to relay his views regarding the impact of employee engagement on the effectiveness of employees in the organisation. From his response, it can be indeed concluded that high levels of employee engagement will lead to improved employee commitment and effectiveness towards the job.

\begin{abstract}
High levels of employee engagement result in improved employee commitment and effectiveness towards the job and thus creating a motivated workforce that will work together to achieve the common goals of the organization. Our employees work better when they have adequate information released to them and also the freedom to us their initiatives when needed. It is very obvious in our organization because we relate well with our employees and through several performance appraisals, surveys and trainings, we have been able to ascertain the needs of our employees. The clamour for more involvement is what we are presently working upon and we hope to achieve this in few months to come if our strategy is sustained.
\end{abstract}

\section{Opinions on the effect of employee well-being on the organisation's efficiency}

The organisation's HR executive was asked to relay his views on the effect of employee well-being on the organization's efficiency. His response revealed that employee well-being has a significant impact on the organisation's efficiency. 
Like I have mentioned earlier, just as employee engagement spurs efficiency, employee well-being is also a critical part of organizational success. Employee well-being predicts employee outcomes, organizational success, and financial performance. The impact of well-being can manifest itself through productivity, results for customers of the organization, employee retention rates and organisational culture.

In summary, the HR executive was able to address the questions regarding the influence of employees' engagement and individual well-being on the performance of the organization. It was conclusive that employees that were more involved in the organization contributed more than those with lesser involvements. It was also obvious that the well-being of the employees had a significant effect on the performance of the organization.

\subsection{FINDINGS AND DISCUSSION}

Findings and its discussion of this study were grouped for adequate triangulation base on the analysed data and result derived from questionnaire and interview conducted in the organisation. Hence, for clarity purpose, the grouping of findings and its discussions were based on questions raised in the first section of the study.

\subsection{Research Question 1: To what extent does employee engagement affect employee effectiveness?}

Retrieved questionnaire data and information generated through an interview conducted in the organisation revealed that employee engagement has a significant effect on employee effectiveness; as such, the null hypothesis stating that employee engagement has no significant impact on the efficiency ofthe organisation is rejected.

It was recorded that engaging employee is crucial to the organisation's performance. However, the performance of these employees varies based on their educational level. The engaged employees in possession of a college degree have a level of performance that is greater than those seen among employees in possession of a high school diploma or less. Employee engagement does not only increase focus and efficiency, but it also decreases absenteeism rates. Employees that are engaged recognise the importance of their effort in contributing and care about what they do, towards the success of their employer and the performance of the organisation.

These findings corroborate the work of Ellis \&Orensen(2017) from their study on the effect of employee engagement. Opined that an organisation's performance is inclined with employee engagement having discovered a positive correlation between both variables. According to the researcher, the more engaged employees are, the better the performance of the organisation, which is measured by its profitability, productivity, employee retention, efficiency, safety, effectiveness and customer loyalty. In the same vein, in relation to the findings of this study, some authors from their research concluded that employee engagement would lead to improved employee effectiveness and involvement towards respective jobs and thus creating a motivated workforce that will work together to achieve the common goals of the organisation.(Rafferty,2015; Taris\& Schaufeli 2015; Sandhya, 2016)

On another hand, other studies (Brett, 2007; Anitha, 2014; Armstrong et al., 2016) contrasts the findings, instead indicates that organizations should develop a robust performance management system which holds managers and employees accountable for the behaviour they bring to the workplace, place focus on topperforming employees to reduce turnover and maintain or increase effectiveness.

Kumar \&Pansari (2015) opine that for an organisation to be effective using engagement tool, it must involve both its employee and customer. The findings revealed that employee empowerment had a moderating effect on both customer and employee engagement; also, the type of business either business-to-business or business-to-customer, and the nature of the industry were also critical factors that proved to have impacted employee engagement in particular.

\subsection{Research Question 2: What is the impact of employee engagement on organisational performance?}

The set of questionnaires retrieved, and interviews conducted revealed that employee engagement has a significant impact on organisational performance; as such, the null hypothesis stating that employee engagement does not have a significant impact on the effectiveness of employees in the organisation is rejected. From the results, the correlation coefficient table shows a simple model that expresses how employee engagement 
impacted effectiveness. During the interview section, the HR manager was asked to relay his views on the effects of employee engagement on the effectiveness of employees in the organisation. From his response, it can be indeed concluded that high levels of employee engagement will lead to improved employee commitment and effectiveness towards the job. According to him, high levels of employee engagement result in enhanced employee commitment and effectiveness towards the job and thus creating a motivated workforce, that will work together to achieve the common goals of the organisation.

In relation to other studies, these findings corroborate with that of Nassazi(2010) who examined the consequences and antecedents of effective work engagement and well-being in a sample of male and female managers and professionals employed in various organisations and industries in Egypt. The results reveal that on the one hand, the antecedents were based on the demographic situation as well as workplace conditions surrounding the employee coupled with the factors that are measured by the need for achievements and workaholic circumstances, while on the other hand, the consequences were based on factors that measured job satisfaction and the psychological well-being of the employee. The results indicated that first; both needs for achievement and one workaholic job behaviour are found to predict all three engagement measures. Second, workplace outcomes or performance were predicted by the degree of employee engagement (e.g. job satisfaction, intent to quit). Third, engagement, again, particularly commitment, predicted different psychological wellbeing outcomes but less strongly than these predicted work outcomes. Other studies (Jamie \&Alan 2014; Bakar \&McCann 2015; Paluku, 2016) on employee engagement, stated that employee engagement is worth pursuing as a means of improving working lives and company performance. Therefore, an organisation should recognise employees more than any other variables, as powerful contributors to its competitive advantage.

On the contrary, Biloch and Lofstedt (2013), Sandhya (2016), Maplecroft, (2010) opined that engagement itself is a barrier to better performance if it's taken to an extreme. They argued that when employees are too focused on getting along, they will probably not care so much about getting ahead, and as it relates to the consequences of having too much good being displayed meaning that employees tend to increase their psychological attributes which could become problematic at very high levels; this includes creativity turning into eccentricity, ambition transforming into greed, and self-esteem gravitating towards narcissism.

\subsection{Research Question 3: To what extent does employee well-being affect an organisation's efficiency?}

Information gathered through interviews and retrieved questionnaire from the organisation's staff revealed that employee well-being affects an organisation's efficiency significantly; as such, the null hypothesis stating that employee well-being does not affect the efficiency of the organisation is rejected.

The analysed data from the retrieved questionnaire presents a simple model that expressed the extent to which employee well-being affects the efficiency of the organisation. Interview section with the HR manager also revealed that employee well-being has a significant impact on the organisation's efficiency. Hence, employee well-being is a critical part of organisational success which predicts employee outcomes, organisational success, and financial performance. The impact of well-being can manifest itself through productivity, results for customers of the organisation, employee retention rates and organisational culture.

The findings of this study corroborate the finding of Alan, (2014) that examined the impact of individual well-being on organisational performance. The study found in general that individual well-being in a vital tool to enhance organisational performance. According to the study, it was evident that the effectiveness of organizations depends on the rate of employees' productivity; as such, it is often the responsibility of the organization and specifically the HR department to constantly carry out examinations via surveys, personal interviews, observations, and performance appraisals to monitor the rate of productivity and level of employee motivation towards discharging their duties.

Schaufeli (2015) also opined that employees that are well catered for often tend to be more productive than those on the other end. The study acclimatized with the need for employers to get involved in helping their employees beyond work duties by showing professional considerations depending on the level of distractions that are being faced by individual employees. It was further implied that the level of individual or collective productivity is tantamount to the amount of job satisfaction and particularly the level of employee well-being. Employee well-being was therefore, ascertained to have a greater effect on individual employees as it dictates the level of productivity which in turn affects the level of organizational effectiveness. 
In the study of Soane (2017), it was asserted that for organizations to thrive and engage their employees optimally there is a need for the organization to ensure that the employees are often in the right state of mind. It was opined that employees with low level of motivation to work are very likely to reduce their level of productivity which adversely affects the performance of the organization. It was further revealed that one of the causes of the low level of motivation to work arises from the inability for organizations to decipher and be sensitive to the attitude or behaviour of individual employees at a certain period of time which has a significant effect on the level of productivity. Organizations were therefore admonished to always carry out constant reviews of their employees particularly on how they feel about the job they have been assigned.

Essentially, the findings and discussion of this study validated Resource-Based View (RBV) and Builtto-Change Theory (BCT). The two theories identified by the researchers focused on performance enhancement concerning the internal and external environment, the resource-based view is concerned with the pool of resources and capabilities as the primary determinants of strategy and performance. Which further stated that the role of human resources in producing firm-wide results should be taken into consideration. It was further stated that managerial resources are not necessarily scarce unless there is a specific attribute that is not found in any other firm; as such, the resource-based view emphasises that the uniqueness of each company as a critical factor for profitability and that exploiting these differences will maintain and sustain competitiveness. Also, the competency model has become a preferred model for identifying a set of skills, knowledge and values that will align human resources with the organisation's strategy (Hamel \& Prahalad, 1994; Armstrong et al., 2016). It has, therefore, become an essential factor for achieving an organisation's overall strategy geared towards fulfilling its set objectives. It can be concluded that the RBV suggests that human resource systems can contribute to organisational performance. In the same vein, Built-to-Change Theory (BCT) opined that human capital is critical for a competitive advantage in the BCT for organisations; there is a recognition that market value rests with human capital. Research has shown that the impact of a firm's human capital management practices, such as training programs and employee engagement efforts to create an excellent place to work and reward systems do produce superior results. Competitive advantage has been evidenced to also rely significantly on the human resource of an organisation rather than competing from tangible resources. The BCT developed by Bakar \&McCann (2015) is a continuous change and adaptive method that consists of environmental scenarios and three primary organisational processes - strategising, creating value and designing - which all revolve around the organisation's identity. Organisational capabilities must be created so that change is the key to success. This can be accomplished through the building of appropriate structure and configuring proper employee engagement and individual well-being.

These theories, therefore, are essential to understanding that organisations need to keep the right people and utilise them through appropriate engagement and well-being tools to spur satisfaction and increased performance.

\subsection{CONCLUSIONS AND RECOMMENDATIONS}

Employee engagement and individual well-being matters to both the employee and the organization as a whole. Regardless of the industry, size, or location, many companies struggle to unlock the perplexities of why performances vary from one workgroup to the other. An organization that is bound to compete effectively in this highly competitive business environment needs to employ appropriately employee agreement and individual well-being as a tool to enhance the attainment of the organisational goals and objectives.

This study measures the significance of employee engagement and individual well-being on organisational performance. Three hypotheses were postulated to achieve the set objectives of the study and answer the research questions. The results derived shows that employee engagement and individual well-being has a significant effect on organisational performance positively.

Based on the finding of this research, the following recommendations for actions were made.

- Top management of organisations should keep in mind employee engagement various drivers such as empowering the employees, providing full information, support from the top management, aligning efforts with strategy while planning to engage their employees to ensure efficiency and improved performance in their organisation. 
- Secondly, communication within the organisations should focus more on engaging employee, individual well-being, empowering employees, and building a bond between leaders, rewards and recognition and employees as strategic objectives.

- Thirdly, managements at all levels should leverage on employee engagement strategies in the organisation. This study revealed that the effective application of employee engagement and individual well-being strategies would assist the organisation to enhance its performance

- Finally, organisation leaders should adopt a periodic survey with employees to develop a better understanding of the employees' expectation trends over time. Monitoring and tracking employee engagement strategies of an organisation and its competitors can be useful when planning to implement effective employee engagement strategies.

\section{REFERENCES}

[1] Abel, M. (2013). Thesocial and financial benefits of developing employee satisfaction. International Journal of Management \& Information Systems, 17, 83-88.

[2] Alonso, A. D., \&Kok, S. (2018). A resource-based view and dynamic capabilities approach in the context of a region's international attractiveness: The recent case of Western Australia. Local Economy, 33(3), 307-328.

[3] Anaza, N. A., \& Rutherford, B. (2012). How organisational and employee-customer identification, and customer orientation affect job engagement. Journal of Service Management, 23(5), 616-639.

[4] Anitha, J. (2014). Determinants of employee engagement and their impact on employee performance. International Journal of Productivity and Performance Management, 63(3), 308-323.

[5] Armstrong, D., Shakespeare-Finch, J., \& Shochet, I. (2016). Organisational belongingness mediates the relationship between sources of stress and post trauma outcomes in firefighters. Psychological Trauma: Theory, Research, Practice, and Policy, 8, 145-165.

[6] Bakar, H. A., \& McCann, R. M. (2016). The mediating effect of leader-member dyadic communication style agreement on the relationship between servant leadership and group-level organizational citizenship behavior. Management Communication Quarterly, 30(1), 32-58.

[7] Barney S.H. (1991). Theory of organisations. Journal of Management Studies, 49, 1194-1220.

[8] Choy, L. T. (2014). The strengths and weaknesses of research methodology: comparison and complimentary between qualitative and quantitative approaches. IOSR Journal of Humanities and Social Science, 19(4), 99-104.

[9] Ellis, F. \&Orensen, J. (2017).Supporting workplace learning for high-performance work. International Labour Organization.

[10] Fairlie, P. (2014). Meaningful work, employee engagement, and other key employee outcomes: implications for human resource development. Advances in Developing Human Resources, 13(4), 508-525.

[11] Hamel, M. \& Prahalad, K.M. (2015). Empirical analysis or organisational justice towards employee's customer-oriented behaviour: A case study of medical institutions in Pakistan. African Journal of Business Management, 5, 1286-1292.

[12] Heilman, D. \& Kennedy-Philips A. M (2011). Employee engagement, human resource management practices and competitive advantage: An integrated approach. Journal of Organizational Effectiveness: People and Performance, 2, 7-35.

[13] Jamie, G.A \& Alan, S.N. (2014). What do we really know about employee engagement? Human Resource Development Quarterly, $25(2), 155-182$.

[14] Kibui, M. E. (2015). Exploring the process of ethical leadership: the mediating role of employee voice and psychological ownership. Journal of Business Ethics, 107, 21-34.

[15] Kimura, T. (2011). Empowerment, P-O fit, and work engagement: a mediated moderation model. European Journal of Economics, Finance and Administrative Sciences, (38), 44-58.

[16] Kumar, H. \&Pansari, M. (2016). Competitive advantage through engagement.Journal of Marketing Research, 53(4), 497-514.

[17] Levitt, H. M., Motulsky, S. L., Wertz, F. J., Morrow, S. L., \&Ponterotto, J. G. (2017). Recommendations for designing and reviewing qualitative research in psychology: promoting methodological integrity. Qualitative Psychology, 4(1), 2-22.

[18] Othman, N., \&Nasurdin, A. M. (2012). Social support and work engagement: a study of Malaysian nurses. Journal of Nursing Management, 462-478.

[19] Paluku, G.I. (2016). Keeping the best: a practical guide to retaining key employees. United Kingdom: Grantham Book Services. 
[20] Plowman, (2013). Organisational belongingness mediates the relationship between sources of stress and organisation outcomes in firefighters. Psychological Trauma: Theory, Research, Practice, and Policy, 8, 145-165.

[21] Rafferty, J. E. (2015). Work engagement: a quantitative review and test of its relations with the task and contextual performance. Personnel Psychology, 64(1), 89-136.

[22] Rafferty, S. Maben, R.T., West, P \& Robinson, H. (2015). Work engagement: reflections on the state of play. European Journal of Work and Organizational Psychology, 20(1), 74-88.

[23] Reio, T. G., \& Sanders, R. J. (2011). Thinking about workplace engagement: does supervisor and coworker incivility really matter? Advances in Developing Human Resources, 13(4), 462-478.

[24] Rich, B. L., Lepine, J. A., \& Crawford, E. R. (2016). Job engagement: antecedents and effects on job performance. Academy of Management Journal, 53(3), 617-635.

[25] Ronald, J. B., \&Ghada, E.K. (2010). Work engagement among managers and professionals in Egypt: potential antecedents and consequences. African Journal of Economic and Management Studies, 1(1), 42-60.

[26] Sandhya, S. (2016). Individual factors and work outcomes of employee engagement. Procedia-Social and Behavioral Sciences, 40, 498-508.

[27] Saunders, M., Lewis, P. \& Thornhill, A. (2016). Research methods for business students. Harlow: Pearson Education Limited.

[28] Shuck, B., Reio, T. G., \& Rocco, T. S. (2014). Employee engagement: an examination of antecedent and outcome variables. Human Resource Development International, 14(4), 56-72.

[29] Soane, E., (2017). Development and application of a new measure of employee engagement: the ISA engagement scale. Human Resource Development International.

[30] Sofian, S. (2016). Individual factors and work outcomes of employee engagement. Procedia - Social and Behavioral Sciences, 40, 498-508.

[31] Taris, T.W. \& Schaufeli, W.B. (2015) Van Veldhoven, M., Peccei, R. (eds.), Well-being and performance at work: The role of context, pp. 15 - 34

[32] Vogelgesang, G. R., Leroy, H., \& Avolio, B. J. (2013). The mediating effects of leader integrity with transparency in communication and work engagement/performance. The Leadership Quarterly.doi: https://doi.org/10.1016/j.leaqua.2013.01.004 